\title{
Neues über die Varietäten des Saamischen
}

LARS-GUNNAR LARSSON 2012: Words and Varieties. Lexical VariGrenzen und Gruppierungen im ation in Saami. Das erstere konzenUmesamischen. Veröffentlichun- triert sich auf einen Dialekt/eine gen der Societas Uralo-Altaica Sprache, während das letztere das Band 83. Wiesbaden: Harrasso- gesamte saamische Sprachgebiet witz Verlag. 198 S.

HÅKAN RyDVING 2013: Words and Varieties. Lexical Variation in Saami. Mémoires de la Société Finno-Ougrienne 269. Helsinki: Société Finno-Ougrienne. $218 \mathrm{~S}$.

Die Dialektforschung ist aus der Hauptströmung der westlichen Linguistik herausgefallen, als wären die Dialekte bereits gründlich erforscht. Die Varietäten der kleineren uralischen Sprachen bieten jedoch weiterhin ungelöste Rätsel und neue Erkenntnisse. Innerhalb von zwei Jahren sind zwei Werke erschienen, in denen die Dialektgrenzen des Saamischen vor allem anhand der Lexik beleuchtet werden, Lars-Gunnar Larssons Grenzen und Gruppierungen im Umesamischen und Håkan Rydvings

\section{Die Grenzen des Umesaamischen}

Lars-Gunnar Larsson zufolge ist das Grundproblem der Erforschung des Umesaamischen der geringe Umfang des verwendeten Materials: Alles, was wir über das Umesaamische wissen, basiert auf einem einzigen Werk, dem von Wolfgang Schlachter 1958 veröffentlichten Wörterbuch des Waldlappendialekts von Malå und Texte zur Ethnographie. Dieses Werk wiederum beruht auf der 1940 aufgezeichneten Sprache eines einzigen Informanten, des aus Setsele stammenden Lars Sjulsson. Durch den Vergleich dieses Idiolekts mit dem Material der Nachbardialekte (oder -sprachen) wurden die wesentlichs- 
ten Besonderheiten des Umesaamischen und die Isoglossen, die es von anderen Sprachformen unterscheiden, definiert.

Das Gebiet, in dem Umesaamisch gesprochen wird, ist durch die kulturelle Aufteilung in Gebirgs- und Waldsaamen gekennzeichnet, denn bei einem Teil der Bevölkerung dieses Gebiets handelte es sich um mit ihren Rentierherden nomadisierende Saamen, bei einem Teil wiederum um ortsgebundene, in Hütten wohnende Fischersaamen. Im 16. Jahrhundert waren beide Gruppen etwa gleich groß. Das Sprachgebiet grenzt im Norden an das Arjeplogsaamische (oder Pitesaamische), im Süden an das Südsaamische. Die Zuordnung der Saamen zu den verschiedenen Gruppen orientierte sich in Schweden lange an der administrativen Gliederung in Lappmarken. Wie Larsson bereits am Anfang seines Werkes feststellt, hält sich das Verbreitungsgebiet des Umesaamischen nicht an die Grenzen der Ume-Lappmark. Er beschreibt die Geschichte der Kolonisation des Gebiets, an der auch die finnischen Siedler beteiligt waren, die von der zweiten Hälfte des 18. Jahrhunderts an die Waldsaamen in die Enge trieben, sodass die Saamen bereits von den 1820er Jahren an in ihrem ursprünglichen Siedlungsgebiet in der Minderheit waren. Die Gebirgs- saamen waren von der Besiedlung des Gebiets und von der Assimilierung der Saamen nicht betroffen, doch die waldsaamische Bevölkerung verringerte sich rasch und war in den 1950er Jahren fast völlig verschwunden. Dieser Prozess wurde auch durch die auf Assimilation abzielende staatliche Politik gefördert, die jedoch die Gebirgssaamen nicht betraf. Am längsten blieb das Waldsaamentum gerade in der Ume-Lappmark erhalten.

Larssons Ziel ist es, einerseits die Grenzen des Verbreitungsgebiets des Umesaamischen festzustellen, andererseits eventuelle Dialektunterschiede innerhalb des Gebiets aufzuzeigen. Da es kaum noch Sprecher gibt, muss er auf altes Material zurückgreifen. Larsson hat in Uppsala und Umeå im Institut für Sprache und Folklore (SOFI) und im Handschriftenarchiv der Universitätsbibliothek Uppsala Sprachmaterial aus neun Ortschaften des Gebiets gefunden, das in den ersten Jahrzehnten des 20. Jahrhunderts gesammelt wurde. Dieses Material wurde vor allem von K. B. Wiklunds Schülern Nils Moosberg und Axel Calleberg gesammelt. Larsson stellt sie und ihre Informanten vor.

Larssons Untersuchung verfolgt das Ziel, vor allem anhand der lexikalischen Variation die Dialektgrenzen des Umesaamischen und 
die Gruppierungen der Dialekte aufzuzeigen, denn die phonologischen oder morphologischen Isoglossen sind in dieser Hinsicht nicht so beweiskräftig wie die Lexik und ihre Variation. Diese lassen die Kommunikationswege und die darauf gründenden Unterdialekte erkennen. Larsson hat u. a. auch die Dialekte von Ullisjaure und Süd-Tärna einbezogen, obwohl sie keinen Stufenwechsel aufweisen und deshalb allgemein zum Südsaamischen Dialekt gezählt wurden - zumal beide südlich des Flusses Umeälven angesiedelt sind. Nach Larssons Ansicht genügt ein einziges lautliches Kriterium nicht für die Bestimmung eines Dialekts, und unter den geografischen Barrieren, die Dialekte trennen, sind die Wasserscheiden wichtiger als die Flüsse.

Obwohl Larsson den Fokus auf die lexikalische Variation richtet, behandelt er auf der Basis seines Materials auch die phonologischen Isoglossen und weist nach, dass der Stufenwechsel je nach dem Unterdialekt variiert und in vielen Dialekten schwankend ist. Er betrachtet auch morphologische Isoglossen (u. a. die Formen des Genitivs und Akkusativs, die Distribution der Illativvarianten, die Bildung von Potential und Konditional) sowie einige syntaktische Eigenschaften.

Nachdem Larsson aus dem verwendeten Wortschatzmaterial u. a.
Spezialtermini (z. B. Rentierzucht), Namen, unklare oder schriftsprachliche Wörter ausgeschieden hat, verbleiben ca. 800 Wörter, in denen eine Variation zwischen mindestens zwei Dialekten auftritt. Die Anzahl der an allen neun Belegorten begegnenden gemeinsamen Wörter beträgt ca. 140. Unter Wort wird hier eine Form und ihre Bedeutung verstanden. Es handelt sich um eine statistische $\mathrm{Me}$ thode, d.h. wenn die Unterschiede und Übereinstimmungen der Wörter erfasst sind, lässt sich auf dieser Basis die Distanz der Dialekte voneinander berechnen. Die Distanzen beschreibt Larsson mithilfe von Radardiagrammen, die gleichzeitig die Gruppierungen der Dialekte sichtbar machen. Die Untersuchung der Lexik zeigt also die Zusammengehörigkeit der Dialekte auf, anders als die Isoglossen, die die Dialekte voneinander trennen.

Aufgrund seiner Analyse gliedert Larsson das Umesaamische in zwei klare Hauptdialekte, den West- und den Ostdialekt. Der Westdialekt wiederum gliedert sich in zwei Teile: zu dem einen gehören Süd-Tärna, Nord-Tärna und der Gebirgsdialekt von Sorsele und $\mathrm{zu}$ dem anderen Ullisjaure, der sich von den anderen unterscheidet. Die Unterschiede sind jedoch nicht durch das Südsaamische zu erklären, sondern sind Larsson zufolge 
möglicherweise ein Ausdruck der Archaik des Dialekts: Ullisjaure ist ein altes waldsaamisches Dorf. Den Ostdialekt repräsentieren Malå, Maskaure, Arvidsjaur, Malmesjaure und der Walddialekt von Sorsele. Zum Kerngebiet der Waldsaamen gehören gerade Malå, Malmesjaure und der Walddialekt von Sorsele. Im wald- und gebirgssaamischen Material finden sich auch Unterschiede. Als Rentierzüchter haben die Gebirgssaamen mehr Einflüsse aus anderen Dialekten übernommen, weil sie sich zwischen verschiedenen Gruppen bewegten.

Ich habe hier nur die wichtigsten Ergebnisse des Buches angeführt. Alles in allem enthält Larssons Untersuchung eine immense Menge an detaillierten Informationen u. a. über das Umesaamische, über die verwendeten Archivmaterialien und ihre Sammlung, allgemeine Überlegungen zu Dialektunterschieden, zur semantischen Entwicklung der Wörter, wie zum Beispiel dem Wandel von Synonymen zu Hyponymen und dem Einfluss von Lehnwörtern auf diesen Prozess sowie zur Entstehung semantischer Distinktionen. Der Text ist präzise und reflektierend und bietet dem Gehirn des Lesers zahlreiche Anregungen. Grenzen und Gruppierungen im Umesamischen ist schöne Philologie, deren Lektüre erfrischt wie klares Wasser.
Das saamische Material des Atlas Linguarum Europae als Ausdruck der Dialektunterschiede

Håkan Rydving arbeitete vor rund dreißig Jahren, Ende der 1970er Jahre, als Sammler und Redakteur des saamischen Wortschatzes des Atlas Linguarum Europae (ALE) mit Lars-Gunnar Larsson zusammen. Für den gesamteuropäischen Sprachatlas wurde Material aus allen Sprachen und Hauptdialekten Europas gesammelt. Bei diesem Projekt wurden 546 Begriffe betrachtet. Es handelt sich vorwiegend um onomasiologische Fragen, aber einige beschreiben auch die semantische Motivation der Wörter. Im saamischen Sprachgebiet gibt es insgesamt 34 Belegorten, die sich in Norwegen, Schweden, Finnland und Russland befinden. Rydving betont - wie Larsson die Bedeutung des Wortschatzes bei der Untersuchung von Dialektunterschieden und -übereinstimmungen.

Bei der Skizzierung seiner Untersuchung referiert Rydving die Geschichte der Erforschung der saamischen Dialekte komprimiert, aber effektiv auf weniger als 6o Seiten (Kap. 2, S. 27-82). Diese Darstellung nimmt mehr als ein Viertel des Buches in Anspruch und würde sich als prägnante Einführung für alle eignen, die sich für die Dialek- 
te des Saamischen und ihre Erforschung interessieren.

Ein kurzes Kapitel widmet Rydving der Erörterung terminologischer Begriffe: Geht es um nur eine saamische Sprache, die sich in Hauptdialekte gliedert, oder um mehrere saamische Sprachen? Viele Wissenschaftler saamischer Herkunft sprechen von einer saamischen Sprache ebenso wie von einem Saamenland und einem saamischen Volk, um die Einheit des Volkes und der Kultur hervorzuheben. (Die Tendenz ist also konträr $\mathrm{zu}$ derjenigen in vielen finnischugrischen Völkern in Russland, die eher Dialekte in den Rang eigenständiger Sprachen erheben - allerdings ist in Russland dieses divide et impera -Prinzip Teil der auf die Schwächung der Minderheitsvölker abzielenden Machtpolitik.) Rydving selbst gelangt zu einer sechsstufigen Definition: 1 . Sprache $>2$. Dialektgruppe $>3$. Hauptdialekt $>$ 4. Dialekt $>5$. Unterdialekt $>6$. Regionaldialekt.

Rydving hebt in seiner Untersuchung zwei verschiedene Arten der Analyse hervor: Die eine (Kap. 6) beschreibt die Wortgeografie mithilfe von drei semantischen Feldern (verba dicendi, Bezeichnungen für Donner, Blitz und Regenbogen sowie die Namen der Wochentage). Dieses Kapitel dient dazu, anhand der Beispiele die Komplexität und
Diversität des saamischen Materials des ALE aufzuzeigen und so das Fundament für eine umfassendere Analyse der Dialekte zu legen. In Kapitel 7 wiederum betrachtet Rydving die lexikalischen Unterschiede und Gemeinsamkeiten der Dialekte des Saamischen aus etymologischer Perspektive und nimmt dabei dialektometrische Methoden zu Hilfe. Rydvings sechs Untersuchungsfragen sind konkret und zielen auf die Klärung des Status bestimmter Dialekte ab (zum Beispiel: Sollte das Umesaamische aufgrund seines Wortschatzes als Südsaamisch klassifiziert werden, gehört das Inarisaamische $\mathrm{zu}$ den westlichen oder östlichen saamischen Sprachen, und ist das Akkalasaamische ein Dialekt des Skolt- oder des Kildinsaamischen oder ein von diesen getrennter Hauptdialekt?). In diesem Kapitel betrachtet Rydving neun Sammelstellen, die für seine Fragestellung relevant sind, da ihr Dialektstatus unklar ist.

Rydving erläutert seine dialektometrischen quantitativen Methoden, die sich dem Durchschnittshumanisten nur mühsam erschließen. Die Ergebnisse, die sie erbringen, sind umso interessanter. Rydving zeigt anhand seines Materials die innere Homogenität der westlichen und der östlichen Gebiete auf; sie bilden zwei Hauptdialektgruppen, die sich in ihrer Lexik deutlich 
voneinander unterscheiden. Das Inarisaamische ist enger mit den westlichen als mit den östlichen Sprachformen verbunden. Rydving definiert es als östlichste Varietät des Westsaamischen oder als zwischen Ost und West angesiedelten eigenständigen Dialekt. Die Dialekte des Skoltsaamischen in Finnland bilden seiner Ansicht nach ein Übergangsgebiet zwischen den westlichen und den östlichen Dialekten, denn sie unterscheiden sich augenfällig vom Skoltsaamischen in Russland. Hier wird der Einfluss der Staatsgrenze auf die Differenzierung der Dialekte deutlich sichtbar. Das Akkalasaamische wiederum steht den skoltsaamischen Dialekten in Russland etwas näher als dem Kildinsaamischen.

\section{Aus den Tiefen der Archive ans Licht der Forschung}

Die beiden hier vorgestellten Werke sind aus der Wiederverwertung von Archivmaterial hervorgegangen. Larsson geht in seiner Untersuchung alle Quellen durch, die umesaamisches Material enthalten; zeitlich decken sie Hunderte von Jahren ab. Rydving gründet seine Untersuchung auf Material, das vor mehr als dreißig Jahren für einen anderen Zweck, den europäischen Sprachatlas, gesammelt wurde. Mithilfe ihres Materials eröffnen beide Verfasser neue Perspektiven auf die Beziehungen zwischen den Dialekten des Saamischen. Obwohl die Methoden quantitativ sind, betreffen die mit ihrer Hilfe erzielten Ergebnisse die Qualität der Dialekte und ihre Beziehungen zu anderen Dialekten. Der Finnougristik steht eine nahezu grenzenlose Menge entsprechender Materialien zur Verfügung. So bieten zum Beispiel die umfangreichen Dialektwörterverzeichnisse, die von den Stipendiaten der Finnisch-Ugrischen Gesellschaft vor und nach der Wende zum 20. Jahrhundert gesammelt wurden und später als Wörterbücher erschienen, Möglichkeiten für entsprechende Untersuchungen der lexikalischen Variation. Die innovativen Werke von Larsson und Rydving haben unsere Vorstellung von den Dialekten des Saamischen und deren Beziehungen zueinander auf vielfache Art präzisiert. Hoffentlich inspirieren sie auch Dialektforscher anderer Sprachen, alte Materialien in neuen Untersuchungen mit neuen Methoden zu nutzen. 